\title{
AC 2008-208: COMPARING THE USE OF COMMERCIAL FIRE ALARM CONTROL PROCESSORS AND PROGRAMMABLE LOGIC CONTROLLERS IN A SAFETY AND FIRE PROGRAM FIRE ALARM SYSTEM ENGINEERING COURSE
}

\section{Harry Franz, University of Houston-Downtown}

Prof. Harry Franz is an Associate Professor in the Control \& Instrument Electronics Design Program and Safety \& Fire Program at the University of Houston Downtown (UHD) in Houston, Texas. He has a BSEE and MSEE from the University of Pittsburgh. He holds a current P.E. and is a member of the NSPE and TSPE. He has worked in industry for sixteen years. He is a member of the IEEE and advisor to the UHD IEEE Student Organization. He is also a member the ASEE and ISA. He has been very active in the Tau-Alpha-Pi national ET honor society. 


\title{
Comparing the use of Commercial Fire Alarm Control Processors and Programmable Logic Controllers in a Safety and Fire Program Fire Alarm System Engineering Course
}

\begin{abstract}
The purpose of this paper is to compare the use of commercial fire control processors and programmable logic controllers for a university Safety and Fire program fire alarm system engineering course.

The commercial fire alarm system includes a basic Honeywell Fire Lite Alarm Control Panel system and a Honeywell Fire Lite Addressable Fire Alarm Control Panel system. The logic controllers include the GE Fanuc controllers and the Automation Direct logic controllers. Advantages and disadvantages of the use of the types of logic controller for the fire alarm engineering course are considered. How each type of controller is used in the course and teaching practices that use each type are discussed. Learning strategies for course project work also are given.
\end{abstract}

The students of the fire alarm engineering course often have diverse technical experience and academics. Most of these students also work fulltime in safety and fire or other industrial fields while attending courses at the university. Many of the program graduates will later work in the safety and fire engineering fields. It is important that the students of the fire alarm engineering class upon graduation be familiar with specific commercial fire alarm control units and generic automation control units.

The students work on the fire alarm control in groups of two or three students. The exchange of knowledge within the groups helps to enhance the understanding of both the commercial fire alarm control processors and the automation controllers. The support by other group members also gives confidence to students.

The use of the commercial Honeywell Fire Lite Fire Alarm Control Processor type of unit allows the students to become familiar with actual commercial fire alarm systems. The more intelligent Honeywell addressable control units do require some programming. This also becomes a practical application tool that is pertinent for designs. In addition, the knowledge of particular commercial fire alarm controllers is a very valuable asset for students when they are employed in the filed of safety and fire.

The generic automation logic controllers encourage a more general range of logic programming skills that include programming in ladder logic, statements, and functional blocks. The advantage of the use of generic logic controllers by the students is that it promotes a wide range in the use of logic control concepts for a variety of applications that are beyond applications of specific manufactures equipment.

Student group exercise and project examples are given that use the various logic control units. 


\section{Introduction}

While both educational and industrial software are used in various courses, the focus of this paper is on a prime example, the EET-3334 Electrical Power Systems course.

The goal of the EET-3334 Electrical Power Systems course is to impart knowledge of both theory and application. After the basic electrical power systems circuit theory is completed, the approach used is to impart knowledge of both electrical power system theory and application concurrently. This is accomplished by having the students learn and use the educational software and industrial software together. While this may lead to a few students not learning the software greatly in-depth, the experience has been that most students can meet the challenge of learning more than one software package at once.

The EET-3334 students first learn the basic circuit theory through the use of educational software that includes Multisim and the other similar packages. The students then learn system applications through the use of Visual Basic and LabVIEW software. Traditionally the students have not been required to have prerequisite knowledge of the educational software. Recently, however, many students that enroll in the electrical power system class have previous knowledge of various educational software packages. The electrical power systems students are also not required to have a prerequisite knowledge of industrial software, although a few students that work in the electrical power sector of industry do have prior knowledge of electrical power industrial software.

A virtual electrical power systems laboratory is used in the EET-3334 course in conjunction with the theory and application of the lecture. This virtual electrical power systems laboratory allows a variety of electrical power systems to be designed effectively with minimum cost. In addition, the lab use of industrial software allows the students to practice using a tool that typically is required later when they work in industry. The students in the virtual electrical power systems lab first learn basic theory power theory using the Electronics Workbench / Multisim software. The students then learn to program some small projects by using mnemonics in the Visual Basic software and by using functional blocks in the LabVIEW software. Finally the students use the industrial software in the lab. The overall object of the virtual lab is to allow the students to both gain theoretical knowledge and experience the creation of electrical power systems. In the virtual lab the students also gain experience in the use and operation of software used in industry. 


\section{Background}

The electrical power systems course EET- 3334 of Engineering Technology department contains "basic principles and applications of electrical power systems, power generation, transmission and distribution in utility and industrial systems. Included are lighting, grounding design, motor controls, transformers, and area classification". The course also contains the basic concepts and principles that are used in the applications of specific designs, installations and tests for realworld electrical power systems. In addition, the course contains demonstrations and computer simulation of electrical power systems. Both educational and industrial software are used in the course.

The Electronics Workbench / Multisim software was chosen to be used in the electrical power system course for the basic electrical power systems circuit exercises because it is easy to learn and use. The circuits designed are single phase sources with single phase AC loads that include RL, RC, and RLC circuits. The Electronics Workbench/ Multisim software is next used to create three-phase delta and wye sources with individual delta and wye loads for various three wires and four with systems. Then this software is used to make three-phase loads that have a combination of delta and wye loads.

The Visual Basic software was chosen to be used in the electrical power system course for the intermediate electrical power systems exercises because it is easy to learn and use. An example of an intermediate exercise that uses Visual Basic is the control of AC loads and motor control circuits. The Visual Basic software is next used to create more advanced complex motor control schemes. Then the Visual Basic software is used for the control of multiple motor loads in a system. It should be noted that students often initially choose to use the Visual Basic software because it is very popular and in widespread use in the university.

The LabVIEW software was chosen to be used in the electrical power systems course for the intermediate electrical power systems exercises because it is also easy to learn and use.

The LabVIEW software is used by the students to create panels for systems and controls in a more direct and faster way than the Visual Basic software. Many students, however, are at first reluctant to choose to use LabVIEW software because they are more likely not as familiar with LabVIEW as Visual Basic. After a few weeks of LabVIEW usage, however, most students prefer to use LabVIEW software.

The Intergraph Smart Plant Electrical software, allows the students to learn the use of a tool that is very likely to be required by industry. The Smart Plant Electrical industrial software is designed to be used to create typical electrical power systems. Note that the students found that the use of industrial software typically requires more knowledge of practical application than theory. 
While use of the industrial software is important, overuse of industrial software in a university course would turn it into an industrial training session. The use of industrial software training in a university level course should be limited and supplemented by the use of educational software. Often the educational software should be both a prerequisite and complement to the industrial software.

\section{Methodology}

The Electrical Power Systems course students are required to work individually on the basic exercises, but are allowed to have some interaction with other students. Students familiar with one type of particular software are encouraged to help other students not familiar with that software. The EET-3334 students are required to work individually on the intermediate exercises, but are allowed and even encouraged to have limited interaction with other students. For the course projects the students are assigned to work in groups that usually have three students per group. All the types of software mentioned previously are available on both the classroom and virtual lab computers. Individual student versions of the educational software are also available in the bookstore. It should be noted on the contrary that for all the quizzes, major exams, and the final exam individual testing is strictly used.

Conventional methods are used to acquaint students with the basic electrical power circuit software. Lectures are first given with examples and demonstrations by the course instructor. The students next work along with the instructor demos and then work individually.

The methods that are used to help the students learn industrial software used in the Electrical Power System course are similar to those which are used by professional trainers.

These methods create variety by using an interaction of people and equipment to keep the course pace fresh and alive. Profession trainers give lectures that are intertwined with hands-on labs and training sessions that have interstices that include group efforts.

Even though various methods of teaching and training are used in the electrical power systems course, the course definitely retains the required amount of academic rigor as required by a fouryear B.S.E.T. program. The academic rigor mixed with practical applications creates variety in the course.

\section{Discussion of Student Work}

The students usually work in groups of three as previously mentioned, however if the class is very large then the students work in groups of four. The group size depends directly on the class size. The student group projects are listed below and are shown in figures that then follow.

Automatic Cabling Design project assignment is shown in figure 1-A. The actual student group work is shown in figure 1-B. This project determines the actual cable size that will meet the given parameters. 
DC Motor System Load project assignment is shown in figure 2-A. The actual student group work is shown in figure 2-B. This project determines which motors are required to "run" to meet the given load.

Automatic Power Factor Correction project assignment is shown in figure 3-A. The actual student group work is shown in figure 3-B. This project automatically determines the capacitor bank setting size to correct the power factor to the desired value.

Examples of Student Work

Figure 1-A Automatic Cabling Design Project Assignment

THE AWG SIZE OF CABLE CONDUCTORS IS AUTOMATICALLY CALCULATED AND DISPLAYED FOR VARIOUS INSULATION TYPES AND APPLICATIONS USING THE FOLLOWING INPUT PARAMETERS:

* CONDUCTOR MATERIAL (examples: copper, aluminum)

* INSULATION TYPE (example: XHHW, TW, others)

* WET OR DRY APPLICATION (some cable types have different ratings for wet or dry)

* AMBIENT TEMPERATURE (cable must be derated for higher ambient temperatures)

* CONDUCTOR GROUPING (cable must be derated for groups of higher than 3 conductors)

*TYPE OF LOAD APPLICATION (motor, non-motor, motor-control-center)

*REQUIRED AMPS LOAD LEVEL (ampacity required for the task)

Figure 1-B Automatic Cabling Design Project Student Work 


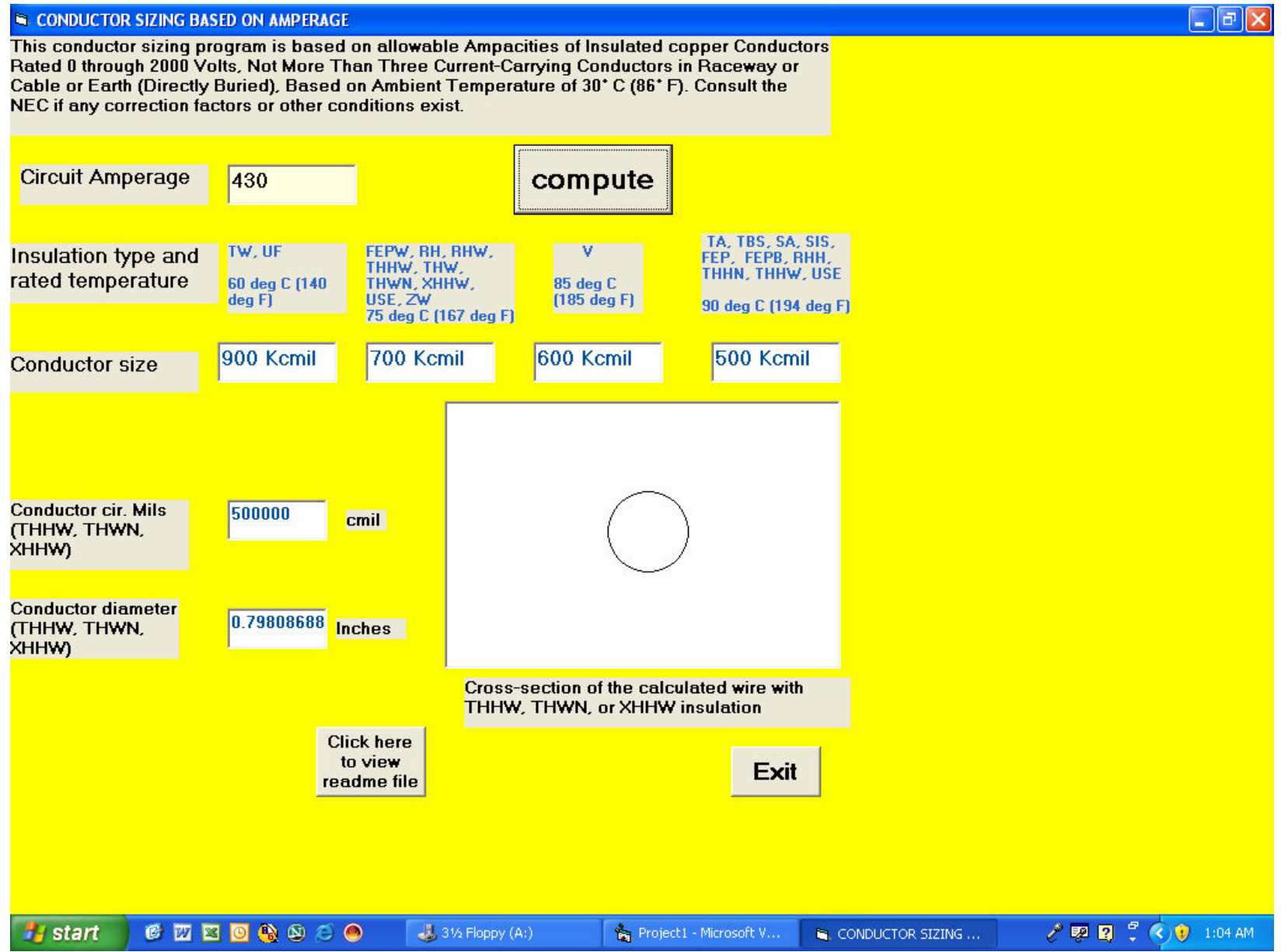

Figure 2-A DC Motor System Load Control Project Assignment

DC MOTOR SYSTEM HAS TWO 10 HP, 120 VDC, 500 RPM RATED MOTORS.

EACH MOTOR IS ONLY $90 \%$ EFFICIENT.

ONE OR BOTH MOTORS “RUN" AT THE SPEED AND POWER TO MEET THE SYSTEM LOAD.

EACH MOTOR "RUNS" UP TO 100\% OF ITS RATED HP TO GIVE A MAX SYSTEM POWER OF 10 HP. WHEN THE SYSTEMS REQUIRES A "HP” GREATER THAN A SINGLE MOTOR CAN OUTPUT, THEN THE OTHER MOTOR MUST ALSO COME ON AND SHARE THE LOAD. NOTE THAT WHEN BOTH MOTORS "RUN" THE LOAD IS SHARED EQUALLY BETWEEN THE TWO MOTORS. ASSUME FOR SIMPLICITY THAT THE HP IS PROPORTIONAL TO SPEED AND THAT EFFICIENCY REMAINS CONSTANT.

THE SYSTEM HAS AN INDICATOR FOR SYSTEM HP LOAD REQUIRED.

THE SYSTEM ALSO HAS AN INDICATOR FOR TOTAL AMPS AND TOTAL WATTS.

IN ADDITION EACH MOTOR HAS A DISPLAY FOR ITS RPM.

SYSTEM LOAD

HP REQUIRED DIGITAL DISPLAY
TOTAL SYSTEM AMPS TOTAL SYSTEM WATTS

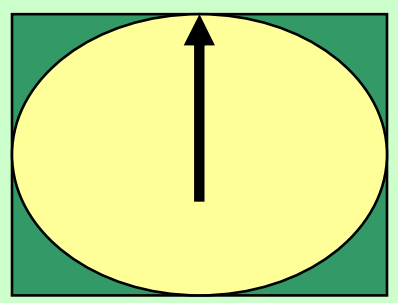

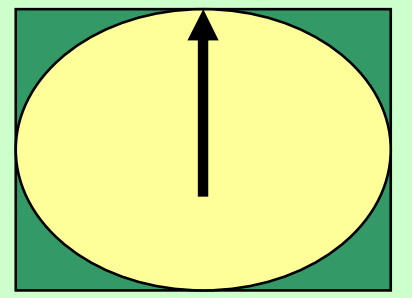



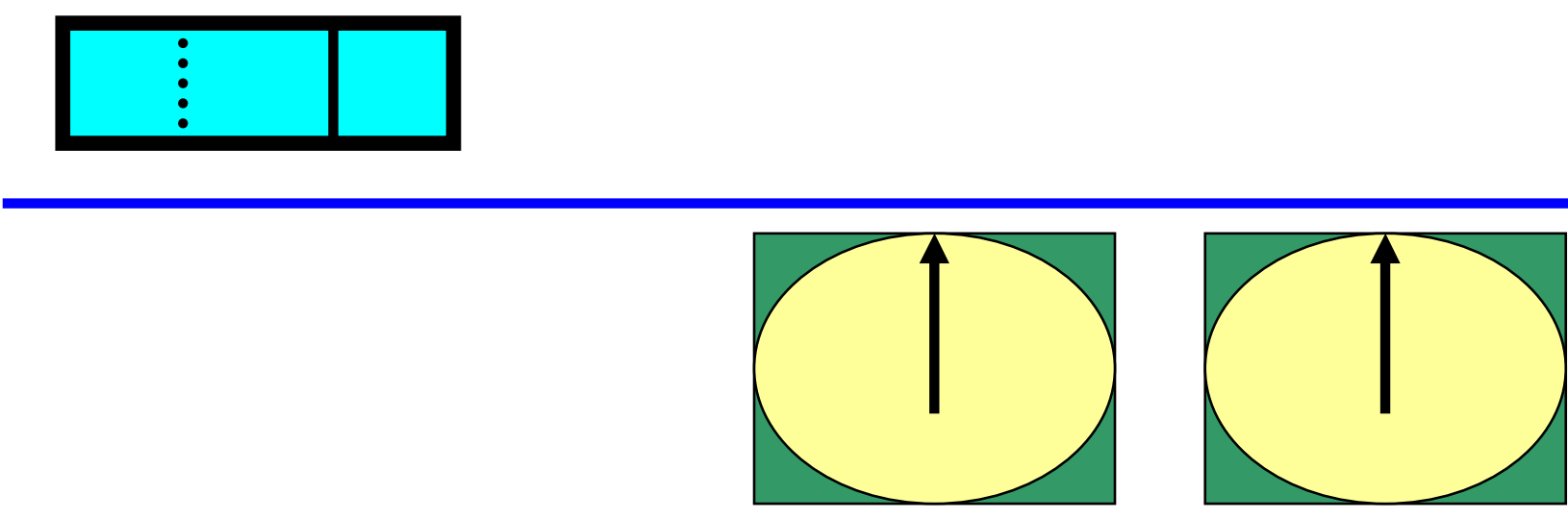

Figure 2-B DC Motor System Load Control Project Student Work

$$
\begin{aligned}
& \text { D } \\
& \stackrel{0}{0} \\
& \mathbb{D} \\
& \vec{\omega} \\
& \vec{\omega} \\
& \overrightarrow{0} \\
& \infty
\end{aligned}
$$




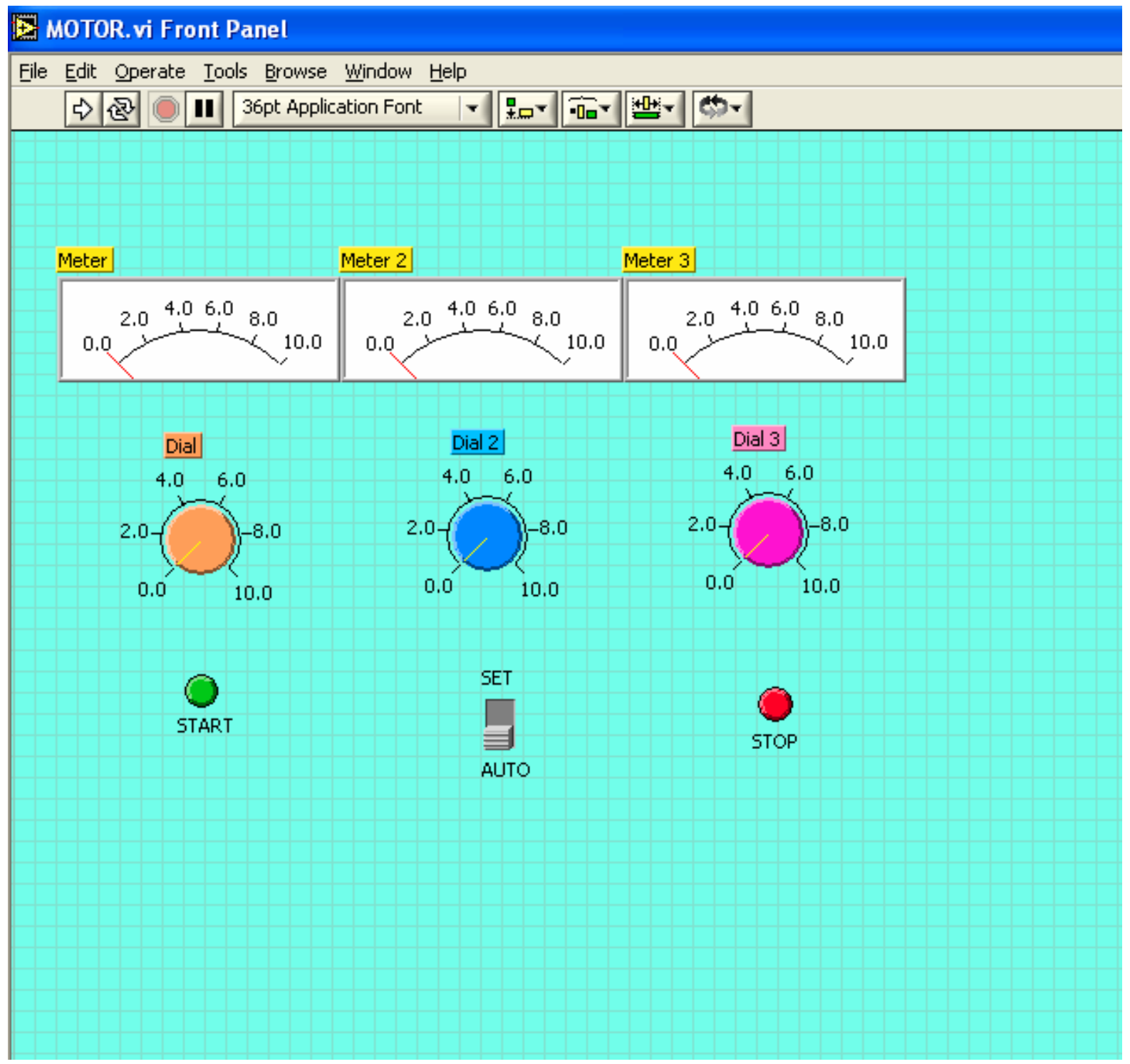

Figure 3-A Automatic Power Factor Correction Project Assignment

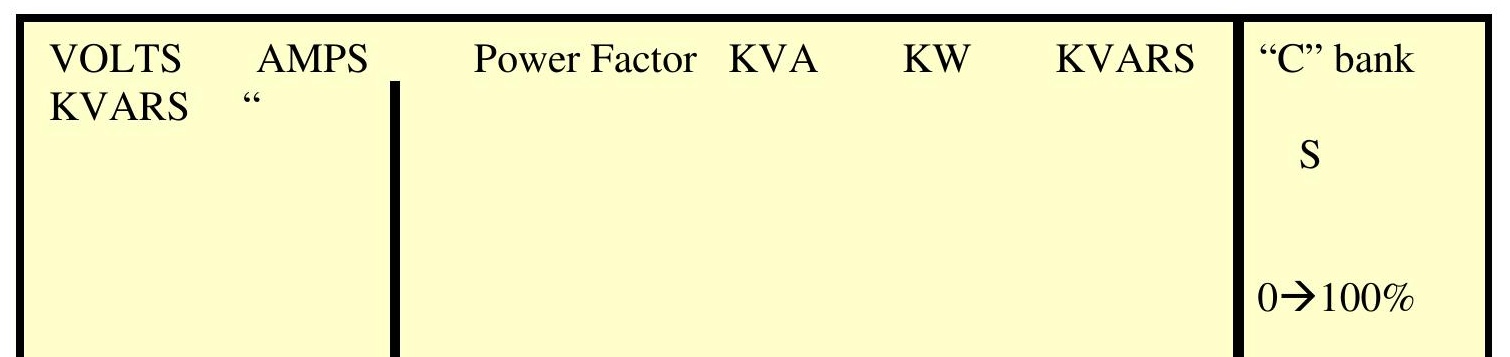




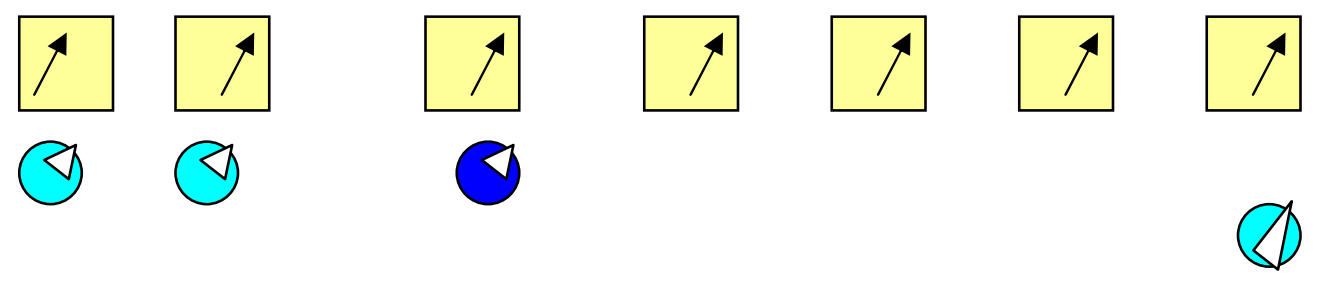

MOTOR LOAD POWER FACTOR CORRECTION SYSTEM USING SOFTWARE THAT WILL CORRECT THE POWER FACTOR TO A DESIRED "SET" VALUE.

FOR LINE FEED :

*THE SYSTEM HAS INDICATORS FOR PLANT LINE FEED VOLTS and AMPS

FOR PLANT LOAD :

*THE SYSTEM HAS INDICATORS FOR PLANT LOAD POWER FACTOR, KVA, KW, KVARS

FOR POWER FACTOR CORRECTION

USING A “C” (CAPACITOR) BANK:

*THE SYSTEM HAS A DIAL TO SET THE DESIRED “CORRECTED” POWER FACTOR

*THE SYSTEM HAS AN INDICATOR FOR THE “C” BANK VARS AUTOMATICALLY ADDED TO THE PLANT LOAD TO CORRECT THE POWER FACTOR

Figure 3-B Automatic Power Factor Correction Project Student Work 


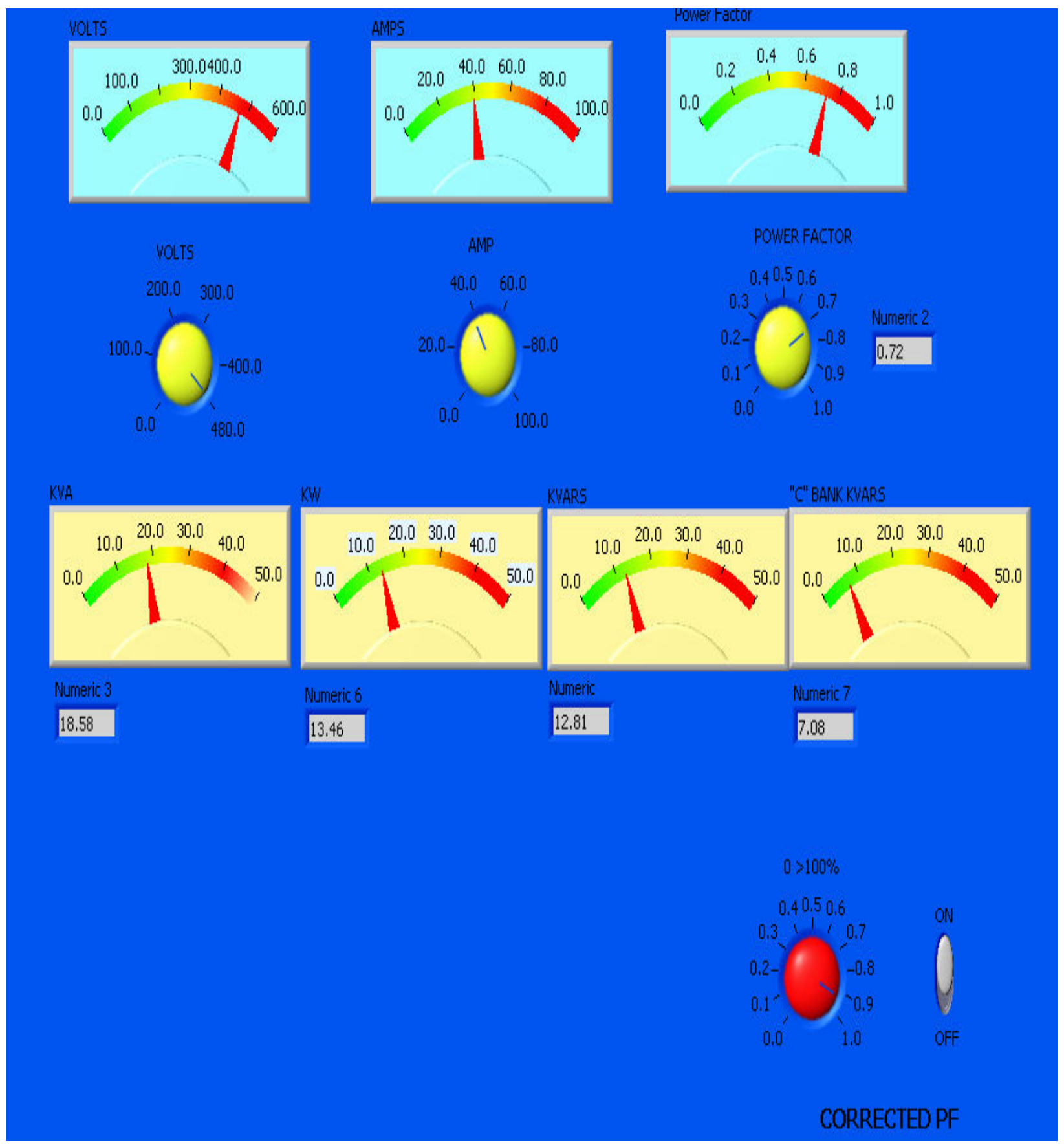

Summary and Conclusions

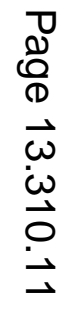


The students in the Electrical Power Systems course definitely benefit from the use of both educational software and industrial software. The main merits of each have been previously discussed, but further examination is worthwhile.

Educational software is usually cheaper and more easily accessed by the individual student. Industrial software is very expensive and often may be affordable only to the engineering technology department. Even then the industrial software is often only obtainable by the university department if it is donated by the software firm.

Also education software is usually made in a more compact student version allowing students to use it on a smaller PC. Often industrial software is not made in "light" or abbreviated versions and requires large computing power that may not be readily available to the individual student or even the engineering technology department.

The Electrical Power Systems course projects require knowledge of the subject matter and knowledge of programming either by mnemonics or function blocks. The educational software allows unique projects to be created. The industrial software in contrast boxes in the student by limiting the project designs that can be made to preprogrammed formats. While the industrial software is fast and efficient within its bounds for industry it is not suitable to be used for the preponderance of an upper level university course. A blend of educational software and industrial software has been found to be the best.

\section{Bibliography:}

1. UHD Undergraduate and Graduate Catalog 2006 / 2007 edition

2. UHD EET- 3334 Students Projects Fall 2006 semester

3. LabVIEW 7i Student Edition National Instruments, Prentice Hall, 2006 edition

4. Learning with LabVIEW by Robert Bishop, Prentice Hall, 2005 edition

5. Intergraph Smart Plant Electrical software manual, 2007 edition 